\title{
Desafios da formação inicial para a docência em História
}

Challenges in initial formation for teaching in History

Margarida Maria Dias de Oliveira* Itamar Freitas ${ }^{\star *}$

\section{Resumo}

Este artigo trata da formação inicial de professores de história no Brasil. Seu objetivo é explorar alguns dos desafios impostos aos gestores de cursos de licenciatura em história. Na primeira parte, apresenta alguns dados da literatura específica no Brasil, Estados Unidos e Europa. Na segunda e na terceira, comenta sobre as carências do atual perfil do formador de professores de história e alguns dos principais obstáculos à construção de currículos de formação inicial condizentes com as necessidades profissionais exigidas, sobretudo, aos docentes da escolarização básica contemporânea.

Palavras-chave: formação de professores; docência em História; ensino de História.

\begin{abstract}
This article deals with the initial formation of history teachers in Brazil. The goal is to explore some of the challenges faced by managers of undergraduate courses in History teaching. The first part presents some data from specific literature in Brazil, the USA and Europe. In the second and third sections, there are comments on the shortcomings of the current profile of the formation of History teachers and some of the main obstacles to the construction of initial formation curricula consistent with the required professional needs, especially for teachers of contemporary basic schooling.

Keywords: teacher formation; teaching in History; History teaching.
\end{abstract}

Este texto discute algumas questões que nos desafiam na tarefa de formar professores de história para os anos finais do ensino fundamental e para o ensino médio. Examinamos problemas relativos ao perfil do formador e aos currículos constituintes da formação inicial.

\footnotetext{
* Universidade Federal do Rio Grande do Norte (UFRN), Departamento de História. BR 101, Lagoa Nova. 59078-970 Natal - RN - Brasil. margaridahistoria@yahoo.com.br

** Universidade Federal de Sergipe (UFS), Departamento de Educação. Campus de São Cristovão. 49100-000 São Cristovão - SE - Brasil. itamarfo@gmail.com
} 
O que nos move, evidentemente, é a constatação de que há algum tempo "alguma coisa parece estar fora da ordem", mas não temos clareza de que coisa é essa e, o pior, não assumimos a responsabilidade sobre o enfrentamento desses problemas. O incômodo com o desempenho dos cursos de graduação em história é experimentado em todo o país e pode ser flagrado em professores e alunos dos mais de seiscentos cursos em funcionamento, durante ou imediatamente após a formação de determinada turma de graduandos. Contudo, é necessário esclarecer que os desafios são coletivos, mas a sua escolha, neste texto, é bastante particular. O que apresentamos aqui são posições mediadas por nossa experiência em departamentos de História e de Educação em universidades públicas e privadas.

Além disso, é importante enfatizar, trata-se de desafios antigos e desafios recentes da experiência brasileira também detectados em outros países. Por isso, na primeira parte, examinamos - sem nenhuma pretensão de revisar exaustivamente a literatura - algumas das maiores preocupações dos professores formadores na literatura recente no Brasil, apresentando em seguida alguns estudos de síntese sobre os Estados Unidos e a Europa. Na segunda parte, dissertamos sobre tais desafios aprofundando alguns pontos que consideramos mais urgentes, concluindo com alguns encaminhamentos e mais questões sobre aquilo que podem fazer os formadores atuais no sentido de enfrentar essas provocações.

\section{DESAFIOS DA FORMAÇÃO INICIAL EM DIFERENTES LUGARES}

Os desafios são prementes, anunciamos, mas a pesquisa não contribui muito para esclarecer esses dilemas cotidianos relativos à formação inicial. Ainda que tenham modificado bastante o seu foco de interesses na última década, ${ }^{1}$ os investigadores do ensino de história permanecem ocupados, dominantemente, com a ação do professor na escolarização básica ou da crítica às políticas públicas para o setor, a exemplo da Rede Nacional de Formação Continuada de Professores (2004), do Sistema Nacional de Formação de Professores (2007) e do Programa Institucional de Bolsas de Iniciação à Docência - Pibid (2010). São indicativos dessa tendência o mais recente dossiê sobre o tema "formação de professores de história", divulgado pela Revista das 
Licenciaturas (2012), e os textos avulsos publicados na mais antiga revista especializada em circulação no Brasil, a História \& Ensino (1995-2012).

Se restringirmos a busca aos profissionais que atuam em departamentos de História ou que frequentaram cursos de pós-graduação na área, o resultado é preocupante, haja vista que, entre os trabalhos que exploram o ensino superior em História, são comuns as teses sobre memória docente (Mattos, 1998) ou história do ensino (Bezerra, 2007; Roiz, 2011) e mais raros os textos que enfrentam desafios atuais (Costa, 2010). Essa carência de pesquisas sobre a formação inicial em história, dentro de programas de pós-graduação, parece nos induzir - a nós professores e alunos da universidade e à comunidade - à equivocada conclusão de que o ensino universitário é, apenas, uma consequência natural das pesquisas empreendidas no seu interior. ${ }^{2}$

Se ampliarmos o campo de busca, chegaremos à constatação de que a pesquisa sobre formação inicial de professores de história é realizada, dominantemente, no interior dos cursos de mestrado e doutorado em Educação. Ainda assim, considerada a quantidade de trabalhos produzidos, no período 2005-2009, segundo informações colhidas e analisadas por Selva Guimarães Fonseca, constataremos que a participação dos pesquisadores da formação de professores de história é ínfima - entre 0,4 e $0,5 \%$ - no cômputo geral dos trabalhos de formação de professor no Brasil. ${ }^{3}$

A raridade da temática também indica que a tarefa de 'pôr o dedo na ferida' da formação inicial em geral tem sido tarefa reservada a pesquisadores experientes. Os desafios mais frequentes vêm sendo traduzidos, nos últimos 5 anos, em termos de desarticulação entre as disciplinas pedagógicas e entre estas e as disciplinas de conteúdos específicos (Cerri, 2006), predominância do conteúdo factual em detrimento de saberes curriculares e saberes relativo às práticas pedagógicas (Martins, 2007), resistência à discussão sobre ensino de história nas universidades de maior prestígio (Ferreira; Franco, 2008) e separação entre a cultura histórica e a didática da história (Cunha; Cardoso, 2011).

São velhos e conhecidos desafios. Mas seriam desafios estritamente brasileiros? Buscaremos minorar, portanto, o caráter impressionista que a lista de questões, inevitavelmente, incorpora quando realizamos esse tipo de inventário. Vejamos o que alguns estudos têm dito acerca das principais problemáticas que circundam os cursos de formação inicial do professor de história em realidades muito distanciadas da brasileira: os Estados Unidos e a Europa. 
Nos Estados Unidos, sabemos, história - do mundo e nacional - é um conteúdo da matéria Estudos Sociais. Assim, compreendemos que algumas demandas cotidianas, manifestas pela American Historical Association (AHA), por exemplo, estejam relacionadas à tentativa de manutenção do espaço reservado à história nos currículos, que também incorpora conteúdos oriundos da psicologia, da geografia, da economia e da política, entre outros (Townsend, 2010). Outra preocupação da AHA é a garantia de profissionais habilitados a manipular conceitos e procedimentos históricos junto aos alunos da high school (Ravitch, 2000). Em 2004, cerca de 52 mil professores tinham a história como principal campo de atuação docente nesses estabelecimentos responsáveis, grosso modo, pelo que corresponde aos anos finais do ensino fundamental e ao ensino médio no Brasil, mas apenas 36\% desses profissionais possuíam formação inicial em história (Townsend, 2008). ${ }^{5}$ Em 2011, estimava-se que cerca de $55 \%$ dos professores de história em atividade não haviam passado pela clássica formação oferecida pelos colleges. ${ }^{6}$

Esses desafios, entretanto, não são exatamente o que procuramos, ou seja, não estão diretamente relacionados ao interior da formação inicial de história. Nesse sentido, são mais rendosos os resultados das investigações de G. Williamson McDiarmid e Peter Vinten-Johansen (2000). ${ }^{7}$ Para esses pesquisadores do ensino, são de duas ordens os problemas relacionados à preparação de professores de história qualificados para a função minimamente exigida pelo cidadão médio estadunidense. A primeira é superar as diferenças culturais entre os profissionais dos departamentos de Educação e de História. A segunda é também superar a resistência das universidades à construção de cursos de formação colaborativa entre departamentos de Educação e de História.

Como o segundo problema é, dominantemente, constituído e alimentado pelo primeiro, vale a pena conhecer as razões apontadas para a divisão entre essas duas instâncias de formação. Para esses autores, os historiadores argumentam que têm objeto claramente definido - a história -, enquanto os professores dos departamentos de Educação justificam sua atuação com base no trabalho com variados campos do conhecimento. Somado a esse problema, digamos, epistemológico, os professores dos departamentos de História veem os colegas da educação com grande desprezo, enquanto estes representam os colegas da história como seres pedantes, mais preocupados com o seu próximo livro que com os próprios alunos. O resultado dessa divisão é o isolamento dos 
futuros professores de história na tarefa de reunir produção do conhecimento histórico com possibilidades de aprendizagem desse mesmo conhecimento histórico (McDiarmid; Vinten-Johansen, 2000).

Considerados os parâmetros - Statement on Teacher Qualifications - publicizados pelo National Council for History Education (NCHE), ${ }^{8}$ poderemos constatar quão distantes estão os formadores estadunidenses de superarem esse desafio. Os referidos parâmetros requerem dos cursos de formação o desenvolvimento das habilidades de conhecer conceitos de política, geografia e economia, conhecer eventos, temas, períodos, ler e usar fontes históricas, compreender e experimentar a pesquisa e a escrita da história, conhecer métodos de ensino e praticá-los sob a tutela de experientes professores de história. No total, as tarefas costumeiramente conhecidas como didáticas ocupam duas das sete expectativas de aprendizagem endereçadas aos cursos de história.

Do outro lado do Atlântico, pesquisadores europeus também expressam suas expectativas e desafios em relação à formação inicial de professores de história. Os modelos de curso são mais numerosos que nos Estados Unidos. Há preparação inicial em universidades, universidades pedagógicas, colleges e escolas politécnicas. E essas iniciativas podem durar 3, 4, 5 anos e meio e até 6 anos. Os desafios em relação às demandas sociais também são diferentes e, hoje, amplamente debatidos pela mídia no Brasil. Países como Albânia, Áustria, Bulgária, República Tcheca, Estônia, França, Hungria, Holanda, Noruega, Portugal, Federação Russa, Espanha e Reino Unido têm demonstrado preocupações no sentido de estimular e induzir os princípios democráticos e a cultura dos direitos humanos entre os seus cidadãos. Cresce também o movimento de combate ao nacionalismo de direita e à força das histórias nacionais frente à história da Europa ou à história do mundo. ${ }^{9}$

Para contribuir com a construção de modernas sociedades democráticas, os especialistas sugerem uma série de competências acadêmicas e de qualificações didáticas na formação inicial do professor de história. Todavia, diferentemente dos 'parâmetros' estadunidenses aqui citados, as expectativas do Council of Europe colocam as qualificações didáticas - planejar, refletir sobre aprendizagens, resolver conflitos em salda de aula etc. - em igualdade numérica com as competências acadêmicas - conhecer historiografia sobre o social e o político, problematizar e criticar conhecimento histórico etc. (Ecker, 2000). 
Não sabemos em que medida essa proposta - disseminada em The structures and Standards of initial training for history teachers in thirteen member states of the Council of Europe: a comparative study (2000) - foi apropriada pelos cursos europeus. Mas temos informações sobre o crescimento da importância do que no Brasil chamamos de 'competências pedagógicas' desde a década de 1970, naquele mesmo território - além de conhecimento da historiografia, da capacidade de transitar por outras áreas, como geografia, sociologia e economia, e também das capacidades de criticar e problematizar. ${ }^{10}$ À época da pesquisa comparada em 13 países europeus, entretanto, apesar da diversidade da oferta, a situação não era muito animadora para o desenvolvimento das qualidades didáticas. Traçado o perfil de centenas de cursos, os especialistas concluíram que entre $70 \%$ e $80 \%$ das horas totais dos cursos de história eram ocupados por 'conhecimentos acadêmicos' em detrimento dos cursos de 'didática geral', dos assuntos de 'didática da história' ou da 'prática de ensino' (Ecker, 2000, p.30). Compreendemos, então, por que alguns pesquisadores têm afirmado que um dos maiores desafios das organizações e dos gestores da formação inicial de professores de história da Europa seria, exatamente, equilibrar competências acadêmicas e competências práticas no mesmo currículo. ${ }^{11}$

Até aqui, revisamos alguns desafios apontados por pesquisadores da formação inicial de história no Brasil, nos Estados Unidos e em alguns países da Europa na década passada. Concluímos, assim, que em contextos bastante diferentes, seja em relação ao lugar da história nos currículos da escolarização básica, seja em termos de modelos de formação inicial, as principais dicotomias são coincidentes. Que fazer, então? Uma saída é naturalizar o problema e dar-nos por vencidos. Outra bem diferente é refletir sobre aquilo que é possível solucionar com as ferramentas de que dispomos. É o que tentaremos fazer no tópico que se segue, como já anunciamos, de forma bastante impressionista. A ideia aqui não é propor um modelo de formação. Nosso intuito é refletir um pouco mais detidamente sobre alguns desafios que nos incomodam diariamente e que nos têm impedido de tomar posições claras e coerentes sobre questões contemporâneas, referentes, por exemplo, às reformas no ensino médio, aos exames nacionais e à produção de expectativas nacionais de aprendizagem histórica. Nossa experiência como formadores nos induz a classificar algumas das 'feridas' dos cursos de formação em dois grandes desafios: a mudança no 
perfil do professor formador e a mudança nos currículos de formação inicial em história, regidos pelos departamentos, faculdades ou cursos de história.

\section{COMO FORMAR FORMADORES SENSÍVEIS} AO TRABALHO DE ENSINAR HISTÓRIA?

Um grande desafio imposto aos responsáveis pelos cursos de formação inicial em história é a formação dos formadores. Até meados da década de 1980, os cursos de história eram constituídos por professores que, de alguma forma, haviam experimentado a docência na escola básica. Não queremos afirmar com isso que eram exemplares na formação. No entanto, apresentavam maior potencial de sensibilização às especificidades do seu trabalho. Com a expansão do sistema nacional de pós-graduação e a exigência do título de doutor para adentrar as universidades públicas - processo que avança de modo mais lento no setor privado - e o rebaixamento dos salários na escolarização básica, os formadores estão entrando cada vez mais jovens nos departamentos de História. Além disso, com o recrudescimento da disputa por financiamento de pesquisas e, consequentemente, por prestígio acadêmico, futuros formadores são cada vez mais ignorantes a respeito das suas tarefas, dado que se empenham na ampliação do seu Currículo Lattes, o qual, bem sabemos, concede ínfimo espaço à experiência docente nos ensinos fundamental e médio.

O resultado dessa mudança de perfil do formador se expressa em seu desempenho como professor, sobretudo nos primeiros 2 anos de atuação. Ele aprende algumas habilidades do ofício trabalhando - empregando os graduandos como 'cobaias' - sem a supervisão de um tutor, já que, não raro, é doutor e professor do quadro efetivo, isto é, um profissional autônomo dentro do seu departamento. Se ele tem 'vocação' ou se emprega o 'modelo do seu último professor' - para utilizar as expressões já criticadas pela pesquisa na área -, os alunos até podem ser beneficiados. Mas se assume que 'não tem vocação para dar aulas' ou que as suas qualificações estão relacionadas à investigação na sua área de doutoramento, o desastre está anunciado. $\mathrm{O}$ desdobramento desse problema aparece em várias situações de trabalho, mas vamos comentar apenas aquelas relacionadas ao primeiro contato com os alunos e às formas de apresentar a matéria e de avaliar as aprendizagens. 
Sobre os primeiros contatos com os alunos, constatamos a perplexidade dos professores frente à familiaridade dos graduandos com as novas tecnologias, sobretudo os serviços de mensagens rápidas e as redes sociais. Os formadores - os que chegam agora aos cursos superiores e os que lá estão - ainda não compreenderam o novo perfil discente. Trata-se de um sujeito que 'nasceu' em ambiente digital - computadores e internet - e desenvolveu novas formas de relacionamento - com pessoas e informações - que alteraram até mesmo o seu modo de produzir ideias. Não desconhecemos a necessidade de discussão de temas como direito autoral e o crescimento de práticas de intolerância na internet, mas vivemos um momento de ruptura com as formas clássicas de apropriação da leitura e formulação de ideias, e isso precisa ser enfrentado pelas universidades. ${ }^{12}$

Em relação à forma de apresentar a matéria, é seguro afirmar que o modo clássico de ensinar nos cursos de história é a aula magistral ou, como a conhecemos no Brasil, a aula expositiva. Os formadores de história se orgulham ao falar que o curso é de história, que a história é uma ciência e, como ciência, tem de ser ensinada cientificamente, ou seja, refletindo os rudimentos do historiador em sua prática - um princípio para lá de centenário. Na prática, entretanto, seja nas disciplinas de conteúdo conceitual/factual - que correspondem à vulgata do ensino básico (história antiga, média, moderna, contemporânea, do Brasil, da América ou do mundo), seja nas disciplinas de conteúdo conceitual/ procedimental - que possibilitam a compreensão dos 'segredos internos' da pesquisa e da escrita históricas (introdução à história, metodologia da história, teoria da história e historiografia brasileira, entre outras), o professor formador é o mais clássico dos clássicos professores adeptos da disciplina formal: concentração do aluno, exposição do mestre, questionamentos do aluno, revisão por parte do professor e avaliação, ou seja, recuperação na memória do aluno, segundo os limites conceituais impostos pelo professor. Dizendo de outro modo, a maioria das atividades da maioria dos professores formadores no Brasil, nos cursos de graduação, pauta-se pela expressão oral, somente. Até mesmo o clássico seminário-oficina que deu fama à formação dos historiadores alemães do século XIX transforma-se em uma exposição individual estruturada em segmentos desconexos do tema a ser explorado.

Nada contra a exposição oral. Ela sintetiza dezenas de obras, permite que o professor vá à Grécia ou à filosofia da linguagem em poucos minutos e volte 
ao assunto em pauta. Ela pode ser reelaborada constantemente para atingir determinado público, coisa que não poderia fazer com a assistência de um filme ou a leitura de um livro, posto que são obras fechadas. Nada contra a exposição oral se ela levasse em conta o que os alunos já conhecem do tema, se fosse instrumento para o desenvolvimento de capacidades como a construção de argumentos ou a montagem de um plano de exposição, entre outros. No entanto, o que observamos, geralmente, é a apresentação de textos - trechos de livros - tal e qual indicados para a leitura. Embora admitamos que a leitura e a interpretação de textos sejam atividades importantes para qualquer profissional, não podemos mais restringir um curso inteiro de 60 ou 90 horas a esse tipo de atividade.

Aliado à exposição magistral - e como desdobramento desta - temos o problema da avaliação a serviço da seleção de alunos. São comuns as provas ditas 'tradicionais' - no estilo perguntas e respostas - com dia e hora rigidamente marcados e objetivos pouco claros, resultando em uma verdadeira operação divinatória por parte dos alunos, sobre o que o professor deles exigirá. Evidentemente, a escrita de resenhas e artigos é empregada como instrumento de avaliação. Elas, no entanto, são exigidas com maior densidade e frequência nos trabalhos de conclusão de curso, monografias e relatórios de estágio. Nesses momentos, observamos a enorme dificuldade dos alunos no desenvolvimento de tais gêneros, exatamente porque, durante o curso, restringiram-se à audição da aula do professor. Quando se lhes exige, por exemplo, a aplicação dos procedimentos da crítica histórica ou o emprego da argumentação, até mesmo os trabalhos de conclusão da licenciatura ganham a forma de uma verdadeira via crucis.

O problema da prática avaliativa com fins de 'caça-talentos' é de ordem política e epistemológica - que é também política. Não é difícil encontrar um professor formador que entenda a 'sua' disciplina como o portal de entrada na carreira de historiador. É uma decisão política e legítima que determinado departamento entenda a teoria da história, por exemplo, como o filtro que deve barrar prováveis 'maus professores' de história. No entanto, é também um dever do professor formador atualizar-se na literatura específica. Há muito a avaliação educacional no interior da universidade deixou de ser - ao menos no plano da pesquisa - um exame de 'corta-cabeças'. Está inscrito na vulgata pedagógica a ideia de que a avaliação é um recurso a serviço da regulação das 
aprendizagens, ou seja, ela informa ao aluno e ao professor formador sobre dificuldades e acertos, alimentando possíveis mudanças de rumo.

Dizer que a avaliação deve estar a serviço da aprendizagem das principais teses sobre a história antiga, dos principais procedimentos da pesquisa histórica e dos valores constitucionais que sustentam a sociedade brasileira significa empregar conceitos e estratégias como diagnóstico, retroalimentação, observação do processo etc. Infelizmente, nenhuma dessas noções pode ser incorporada com a rapidez que merece por uma simples razão: a grande maioria dos formadores é incapaz de responder a perguntas sobre o sentido da expressão 'aprendizagem histórica'.

\section{QUE SABERES SELECIONAR PARA FORMAR O FUTURO PROFESSOR DE HISTÓRIA?}

A seleção dos saberes é um grande desafio porque reflete as identidades do profissional de história e, ainda mais preocupante, da disciplina escolar História. Exploremos algumas das principais dificuldades relativas à elaboração de projetos pedagógicos de história, sobretudo no que diz respeito à natureza dos saberes que devem compor os cursos de formação inicial.

Uma das conquistas recentes da pesquisa sobre o ensino de história - fruto dos debates ocorridos nos últimos 20 anos - é a negação da ideia que reduz a disciplina escolar História a uma transposição pura do conhecimento produzido no campo acadêmico para o ambiente das salas de aula. Consequentemente, um professor formador não pode considerar que prepara o futuro docente apenas apresentando conceitos, acontecimentos, períodos e processos históricos sob a mais atualizada historiografia.

Esse, contudo, não é o entendimento dominante entre os professores formadores no momento em que discutem a elaboração dos projetos pedagógicos dos cursos de licenciatura em história. Neste instante, o debate gira em torno da limitação espaço-temporal ou dos graus e formas de encadeamento da matéria a ser abordada. Em outras palavras, ganha centralidade a disputa pelos marcos que identificam História da América I ou II, a História do Brasil I, II ou III, por exemplo. Da mesma forma, ganha ênfase a discussão sobre os pré-requisitos disciplinares, como se a compreensão do conhecimento histórico 
estivesse restrita ao processo histórico ou à obediência a determinada sequência cronológica.

Nesse jogo de disputas, que também reproduz o interesse de consolidados grupos de pesquisa e de associações de profissionais de história identificados por uma adjetivação - 'de história da América', 'de história colonial', 'de história antiga' etc. - tal forma de seleção dos saberes necessários ao futuro professor de história vai cimentando o tão criticado modelo quadripartite linear de tratamento da experiência do homem no tempo. ${ }^{13}$ Esse ponto é importante porque remete a certa esquizofrenia experimentada pelos formadores. Sabemos que a divisão da história do mundo em quatro grandes blocos - antiga, média, moderna e contemporânea - foi uma invenção da escola e para a escola e já dura mais de quatro séculos. Ela ajudou a estruturar corporações de pesquisadores e acabou por constituir o currículo dos cursos de formação de professor na Europa, ou seja, foi consolidada pela universidade moderna. Nas últimas três décadas, por causas várias que não vamos aqui elencar, passou a receber duras críticas dos professores formadores, que por sua vez foram disseminadas entre os professores da escolarização básica. Dos livros didáticos, no entanto, seu domínio nunca foi abalado, significando dizer que alguma função a divisão quadripartite preenche no cotidiano do professor.

Mas, enfim, onde está a esquizofrenia do formador? Ela está no fato de criticarmos o quadripartitismo dos ensinos fundamental e médio e o praticarmos nos cursos de formação. Dizendo de outro modo, não conseguimos transformar a crítica em mudança efetiva nos currículos da formação inicial. Parecemos enfrentar alguns dilemas: se aceitamos a divisão 'história antiga, média, moderna e contemporânea' como modelo de conhecimentos factuais/ acontecimentais para a formação do professor, temos de encerrar a crítica ao currículo quadripartite da escolarização básica. Se encontrarmos outros arranjos para a discussão dos 'conteúdos conceituais', 'conteúdos factuais' e 'períodos', seremos, provavelmente, convidados a negar a sedutora sugestão de transformar os currículos dos cursos de formação inicial em laboratórios das nossas associações, redes, linhas e grupos de pesquisa.

Afirmamos, então, que um professor formador não deve pensar que forma um professor de história apenas apresentando conhecimentos atualizados sobre a experiência dos homens no tempo - historiografia. É consenso a ideia de que o futuro docente deve compreender os modos de produção do conhecimento 
histórico. Assim, o currículo da formação inicial tem que reservar um tempo para atividades que desenvolvam habilidades relativas às operações processuais da pesquisa e da escrita da história.

Aqui, mais uma vez, somos assaltados por contradições e paradoxos. É consenso que as habilidades de pesquisa e escrita devem ser desenvolvidas. No entanto, as atividades que viabilizam essas aprendizagens raramente ocupam o planejamento dos formadores. Claro que as disciplinas Introdução à História, Métodos e Técnicas de Pesquisa, Teoria da História e as mais diversas variantes estão presentes nos currículos, desde o final dos anos 1950. É também evidente que as disciplinas 'de teoria e método' foram largamente disseminadas nos currículos das licenciaturas em história por toda a década de 1990, como parte de um movimento que pretendia minimizar a dicotomia professor/pesquisador. Ocorre que as atividades que exercitam os alunos nas operações processuais da pesquisa, por exemplo, lembram em grande medida as operações do historicismo alemão e da escola metódica francesa, e tudo o que a maioria dos formadores quer ver distante do seu cotidiano é o fantasma do 'positivismo' - não obstante o equívoco desse rótulo. Além disso, identificação, leitura, comparação, crítica de fontes e construção de argumentos com base em evidências demanda muito esforço, atenção individualizada, compreensão das limitações dos alunos etc., e isso é também motivo para a sua quase exclusão dos cursos de história. O resultado já o apresentamos no tópico anterior: são aulas expositivas, onde predomina a apresentação dos resultados da pesquisa histórica de ponta.

Qual é o problema de focar a formação na apresentação da pesquisa de ponta? A priori, nenhum. Claro que os estudos universitários devem ser atravessados pela investigação científica. Se for possível, durante o curso de licenciatura, produzir conhecimentos originais, ainda melhor. Mas, o que julgamos fundamental é o exercício sistemático da pesquisa com todas as lições que a mais antiga das ideias de aprendizagem nos sugere: errar, corrigir, mudar o rumo, enfim, construir conhecimento. Mesmo que as descobertas sejam novas apenas para os alunos, elas devem ser exercitadas, afinal, o que pode não ser novidade para o professor pode representar uma descoberta transformadora para o aluno. Isso, certamente, terá desdobramentos em sua futura atuação docente.

Mas, só isso - apesar de não ser pouco - resolve a formação do profissional de história? Consideramos que não. Há problemáticas que devem atravessar os cursos de graduação. É necessário conhecer o ambiente escolar, 
vivenciá-lo junto aos alunos de graduação, discutir, propor e participar da execução de políticas públicas que se relacionem com as atividades e ambientes nos quais as reflexões sobre a leitura e os usos do passado no trabalho de formação de pessoas estão em curso. Esses são os casos das ações de preservação, organização e acessibilidade de fontes, políticas de musealização e construções de expectativas de aprendizagem e de avaliação para os diversos níveis de ensino escolar.

Se localizamos a dissociação entre ação e pensamento dos formadores no que diz respeito aos conteúdos conceituais/acontecimentais/procedimentais históricos, também podemos detectá-la a respeito dos conteúdos conceituais/ procedimentais pedagógicos, ou seja, aqueles saberes e habilidades específicos ao trabalho de lidar com a formação de pessoas - um público não adulto. No entanto, constatar a dissociação não implica defender que a formação para a docência se encerre, exclusivamente, nas 'disciplinas pedagógicas'. O ideal é reconhecer que ensinar história é um ofício que se aprende, que os estudos históricos não reúnem todas as informações e procedimentos necessários à formação - disponíveis em áreas como as que fundamentam a pedagogia. Importante é o diálogo e o regime de colaboração. Ele impõe uma barreira à ignorância do professor a respeito dos diversos ângulos de observação e resolução de um problema surgido em ambiente didático. Ele evita a subserviência de uma área a outra - também um tipo de ignorância. Evita, também, a prática corrente em muitas instituições onde os departamentos de Educação prescrevem as orientações sobre a tarefa de ensinar história.

Reconhecer a necessidade de buscar em outras áreas os insumos necessários ao bom desempenho na docência em história significa também apropriar-se da discussão sobre a natureza da disciplina escolar História. Aqui, defendemos que uma das singularidades da disciplina é o seu poder de possibilitar a ampliação da experiência temporal para além do pouco tempo que caracteriza a vida dos seres humanos. A disciplina escolar História, portanto, nos instrumentaliza para comparar e tomar decisões. Essa característica faz do ensino de história um direito extensível a todos os cidadãos. ${ }^{14}$

O apropriar-se da discussão - interessar-se por ela - pode ajudar a reduzir o impacto das equivocadas posições com as quais nos defrontamos no dia a dia: a disciplina escolar História é propriedade dos historiadores ou do Estado? Na primeira, a sociedade é excluída como sujeito demandante de passado. $\mathrm{Na}$ 
segunda, os alunos e os professores da escolarização básica são excluídos como sujeitos demandantes de presente. O ideal é que os cursos de formação incluam conhecimentos sobre os princípios constitucionais relativos à escolarização obrigatória, as limitações e as potencialidades da corporação de profissionais de história na construção das suas finalidades e conteúdos, frente aos diferentes grupos sociais que pressionam pela exclusão, inclusão ou ampliação deste ou daquele valor, deste ou daquele conhecimento.

Reconhecer a necessidade de buscar em outras áreas os insumos necessários ao bom desempenho na docência em história não implica dizer, entretanto, que devamos, necessariamente, migrar para os departamentos de Educação, que tradicionalmente discutem questões relativas à constituição das disciplinas escolares, à natureza do aluno, a formas de apresentação e avaliação da matéria. Há décadas, teóricos da história têm efetuado esse diálogo e sintetizado, com bastante maestria, as teses e procedimentos que possibilitam ao futuro professor enfrentar suas tarefas cotidianas, a exemplo de refletir sobre as diferenças cognitivas entre alunos da escolarização básica e alunos do ensino superior, sobre os mecanismos empregados pelas crianças na rememoração e interpretação do passado, sobre a seleção de experiências básicas para o desenvolvimento de determinados valores e atitudes, sobre formas de organização desses conhecimentos em planos de estudo e currículos, sobre a construção de estratégias de didatização e apresentação que explorem e façam desenvolver determinadas dimensões do humano, sobre a relação entre os conteúdos da formação e os conteúdos exigidos por políticas públicas, entre outras. Os resultados dessas reflexões podem até ser sistematizados em área de pesquisa chamada 'Didática da História' ou qualquer outro nome. Entretanto, não devem ser segregados a um componente curricular do curso de formação e, mais importante, ter como pontos de partida e de chegada a ciência de referência - a história. ${ }^{15}$

\section{Conclusões}

Ao longo deste texto, buscamos convencer os leitores de que ensino/pesquisa, habilidades didáticas/habilidades investigativas, teoria da história/prática de ensino e tantas outras dicotomias apontadas como causas da ineficiência dos cursos de formação inicial em história não são singularidades da experiência brasileira. 
Dissertando sobre alguns desafios com os quais nos defrontamos na formação em departamentos de História e de Educação - e que atravessam tais dicotomias -, apontamos a necessidade de problematizarmos a formação dos formadores, pois é cada vez mais patente, por exemplo, o desconhecimento desse profissional no que diz respeito ao novo perfil do graduando de história, bem como a reprodução sistemática de práticas pedagógicas antiquadas e inadequadas.

Também buscamos explicitar algumas contradições e paradoxos dos docentes envolvidos na construção e administração dos currículos para a formação inicial em história. Comentamos os equívocos de reduzir a preparação dos futuros professores de história à apresentação de informação historiográfica atualizada, de dar as costas aos múltiplos espaços nos quais os alunos experimentam o passado, de sonegar a investigação e a descoberta aos futuros professores.

Neste artigo, por fim, reiteramos a necessidade de o graduando em história conhecer melhor a natureza da disciplina escolar História, apropriando-se dos teóricos da história que refletem sobre esses temas com base na ciência da história. Ratificamos, assim, o pensamento dominante entre os profissionais da história, de que a formação inicial cabe aos departamentos de História.

No entanto, chamamos atenção dos colegas para as seguintes reflexões. Se os profissionais radicados nos departamentos de História pensam ser importante defender a manutenção do atual modelo de formação no interior dos departamentos de História e, consequentemente, sob a tutela de pós-graduados em história, é importante que enfrentem esses desafios imediata e profundamente.

O que temos percebido, sobretudo nos últimos 5 anos, é a intervenção esporádica, pontual e com grandes doses de desinformação por parte dos colegas quando há suspeitas de que a licenciatura em história pode vir a perder espaço e até se transformar em opcional na tarefa de formar os brasileiros dos 11 aos 17 anos em média. Os recentes debates sobre o lugar das ciências humanas no currículo do ensino médio são o exemplo mais recente. Os próximos eventos a provocarem essa atitude de prontidão - seguida por declarada indiferença em relação ao ensino de história - serão, provavelmente, o lançamento das Expectativas de Aprendizagem de História para o ensino fundamental e do Exame Nacional da Carreira Docente.

É mais que urgente a necessidade de os departamentos de História assumirem, efetivamente, que são formadores de professores de história. Da mesma 
maneira, devem os formadores de professores se conscientizar de que são também professores de história. Consequentemente, necessitam conhecer e desenvolver habilidades específicas que não podem ser transmitidas por cópia do modelo da geração anterior ou adquiridos por 'vocação'. Apesar de recorrentes em outros países, como vimos aqui, os desequilíbrios entre as habilidades historiadoras e o emprego dessas habilidades na vida prática - em que a docência em história ocupa importante papel - geram entre nós um impacto negativo muito mais desastroso, uma vez que possuímos apenas um modelo de formação inicial.

\section{NOTAS}

${ }^{1}$ Cf. MARTINS, Maria do Carmo. Currículo e formação de professores de história: uma alegoria. Educação em Revista, Belo Horizonte, n.45, p.145-158, jun. 2007.

${ }^{2}$ Cf. MATTOS, Ilmar Rohloff de (Org.). História do ensino de história no Brasil. Rio de Janeiro: Access, 1998; BEZERRA, Francisco Chaves. O ensino superior de história na Paraíba (1952-1974): aspectos acadêmicos e institucionais. Dissertação (Mestrado em História) Programa de Pós-Graduação em História, Universidade Federal da Paraíba. João Pessoa, 2007; ROIZ, Diogo da Silva. Os caminhos (da escrita) da história e os descaminhos de seu ensino: a institucionalização do ensino universitário de História na Faculdade de Filosofia, Ciências e Letras da Universidade de São Paulo. Curitiba: Appris, 2011. São mais raros aqueles que enfrentam desafios atuais: cf. COSTA, Aryana Lima. A formação dos profissionais de história: o caso da UFRN (2004-2008). Dissertação (Mestrado em História) - Programa de Pós-Graduação em História, Universidade Federal da Paraíba. João Pessoa, 2010.

${ }^{3}$ Cf. GUIMARÃES, Selva. Formação de professores de Historia: reflexões sobre um campo de pesquisa (1987-2009). Cadernos de História da Educação, UFU, v.11, p.285-303, 2012. p.299.

${ }^{4}$ Cf. CERRI, Luis Fernando. Oficinas de ensino de história: pontes de didática da história na transição do currículo de formação de professores. Educar em Revista, Curitiba, n.27, p.221-238, jun. 2006; MARTINS, 2007; FERREIRA, Marieta de Moraes; FRANCO, Renato. Desafios do ensino de história. Estudos Históricos, Rio de Janeiro, v.21, n.41, p.79-94, jun. 2008; CUNHA, Jorge Luiz da; CARDOSO, Lisliane dos Santos. Ensino de história e formação de professores: narrativas de educadores. Educar em Revista, Curitiba, n.42, p.141-162, dez. 2011.

${ }^{5}$ Cf. TOWNSEND, Robert B. What do we know about history in the schools. American Historical Association. Aug. 2010. Disponível em: http://blog.historians.org/ education/1101/what-do-we-know-about-history-in-the-schools; Acesso em: 15 jan. 2013; RAVITCH, Diane. The educational backgrounds of history teachers. In: STEARNS, Peter N.; SEIXAS, Peter; KNOWING, Sam Wineburg. Teaching, and learning History: national and international perspectives - edited. New York: New York 
University Press, 2000. p.142-155; TOWNSEND, Robert B. A portrait of high school history teachers. American Historical Association, Sept. 2008. Disponível em: http://blog. historians.org/education/607/a-portrait-of-high-school-history-teachers; Acesso em: 12 jan. 2013.

${ }^{6}$ FEISTRITZER, Emily. Profile of teachers in the U.S. 2011. Washington: National Center for Education Information, 2011. Disponível em: www.ncei.com; Acesso em: 13 jan. 2013.

${ }^{7}$ McDIARMID, G. Williamson; VINTEN-JOHANSEN, Peter. A Catwalk across the Great Divide: redesigning the History Teaching Methods Course. In: STEARNS; SEIXAS; KNOWING, 2000. p.156-177.

${ }^{8}$ NATIONAL COUNCIL FOR HISTORY EDUCATION. Statement for Teacher Qualifications (Adopted by the NCHE Board of Trustees on Dec. 21, 2006). Disponível em: www. nche.net/teacherqualifications; Acesso em: 13 jan. 2013.

${ }^{9}$ Cf. ECKER, Alois (Org.). The structures and standards of initial training for history teachers in thirteen member states of the Council of Europe: a comparative study. Viena: Council of Europe, 2000.

${ }^{10}$ LEEUW-ROORD, Joke van der. History teacher education in Europe: some issues and case studies. Bulletin Euroclio, n.9, 1997.

${ }^{11}$ Cf. DROSNEVA, Elka; STROTZKA, Heinz. Academic and practical competencies in initial teacher training. In: ECKER (Org.), 2000, p.88-111.

${ }^{12}$ MAYNARD, Dilton Cândido Santos. Intolerância em rede: apropriações da Internet pela extrema-direita (1999-2009). Boletim tempo presente, Rio de Janeiro, v.10, p.3, 2010.

${ }^{13} \mathrm{O}$ quadripartite histórico está referenciado aqui como símbolo da divisão eurocêntrica e da concepção linear da História. Embora considerarmos esta uma divisão possível e que atendeu as perspectivas dos estudos históricos em um momento, o que estamos assinalando aqui é a divisão dos cursos de graduação em História - majoritariamente - somente nesta perspectiva.

${ }^{14}$ COSTA, Emília Viotti da. Os objetivos do ensino da História no curso secundário. Revista de História, São Paulo, n.29, 1957; OLIVEIRA, Margarida Maria Dias de. O direito ao passado: uma discussão necessária à formação do profissional de História. São Cristovão (SE): Ed. UFS, 2011; RÜSEN, Jörn. Razão histórica: teoria da história - fundamentos da ciência histórica. Brasília: Ed. UnB, 2001.

${ }^{15}$ CERRI, Luis Fernando. Didática da História: uma leitura teórica sobre a História na prática. Revista de História Regional, Ponta Grossa (PR), n.15, v.2, p.264-278, 2010; SADDI, Rafael. Didática da História como subdisciplina da Ciência Histórica. História \& Ensino, Londrina (PR), v.16, n.1, p.61-80, 2010.

Artigo recebido em 20 de dezembro de 2012. Aprovado em 14 de abril de 2013. 